\title{
Studies of E-Learning in Practice
}

\author{
https://doi.org/10.3991/ijac.v10i2.7359 \\ Manfred Rechberger \\ University of Music and Performing Arts, Graz, Austria \\ manfred.rechberger@kug.ac.at
}

\begin{abstract}
Computer assisted and computer based applications become more and more important in everyday lives. Their implementation in the field of music education seems to become a long-term project. Whereas years ago we were sure about the fact, that the quality of e-learning at our University of $\mathrm{Mu}$ sic and Performing Arts depends on the implementation of audio-visual media at our e-learning platform, nowadays the text based tasks and written journals have won the race at least in the statistic of usage.

Many modules containing multimedia based content promote creative processes and different learning situations. Advantages of e-learning include flexibility and convenience for learners, especially if they have more variety in learning experiences by using multimedia applications. This paper deals with the change of our user behaviors in the last years, discussion forums, blogs, wikis and collaborative online activities and focuses on tools for musicians, composers and music scientists based on the actual status of the discussions in media pedagogies. A scientific project including surveys about the advantages and disadvantages of digital teaching repositories describes common used online music tools.
\end{abstract}

Keywords-E-Learning, Music Education, Video Feedbacks, Podcasting, Interactive Scores, Studies.

\section{Introduction}

The University of Music and Performing Arts Graz is with about 3300 students an internationally renowned place of education - 17 institutes offer highly qualified training for artistic and scientific professions. Owing to its geographic situation it perfectly knows to combine Austrian tradition in music and performing arts with the creative potential of Eastern and Southeastern Europe.

The e-learning landscape of the university is still very small, several tools for collaboration (Elgg, Loudblog, EyeOS, ...) had to be closed after implementation because of a couple of reasons, cost cuts where the most important ones. Although or even just because we just left Moodle as the one and only e-learning system, we could increase the usage of the platform dramatically. Mostly all of our courses have face- 
to-face contact and we have rarely experiences in blended learning and blended teaching strategies. All of our students have possibilities to use computers at the university, in the last ten years we increased the number of online courses in a blended form from 20 to 160 per year. We have chosen one institute where all vocal performances were going to be filmed and archived in the platform for feedbacks and discussions about improvements within peers and/or teachers.

\section{Collaborative E-Learning with Moodle}

In the past years we never stopped looking for a learning platform tailored to the specific teaching needs at an University of Music and Performing Arts. In 2007 we started with the well known Open Source Learning Management System (LMS) "Moodle". Most of the activities within the platform are text based, whereas the audio and video files requires most of the storage. The audiofiles are self-produced in most cases, which means they have been recorded, mixed and mastered by students. The mixdowns are saved in the platform in high resolution mp3-format (192 kbps), the recordings are handled outside the web based learning environment because of performance improvements. Using local network attached storage allows up to 7 students to work with the same audio material simultaneously. An actual challenge is the integration of streaming videos in browser-based systems. Flash videos are gone, H.264 video codecs in mp4 containers are compressed, acceptable in file size and quality but time stealing in producing when being recorded with HD cameras in very large AVCHD streams. Yet we have no faster work around to get the vocal performances into the web without decoding and tagging in pro video software. But soon this will change: Our brand new model of a Panasonic 360 degree streaming camera is right now being integrated as a ceiling-mounted capture device in one of our performance rooms for evaluation. The next big thing for our small university will be the handling of streamed content in real time over a streaming server for an automatic integration in the corresponding Moodle course.

We are still developing various e-learning scenarios for our university with a special focus on audio and video implementations. In the sense of interactive videos we recorded a concert with music composed by Joseph Haydn and let the audience conduct the virtual orchestra with a Wii remote controller. If your movements are too slow or too fast, the musicians will stop playing and leave the stage - the video will jump to several prepared points in the timeline. Actually we are using a Bluetooth stick and a windows computer to get the movements of the y-axis controlling the flash animation. 


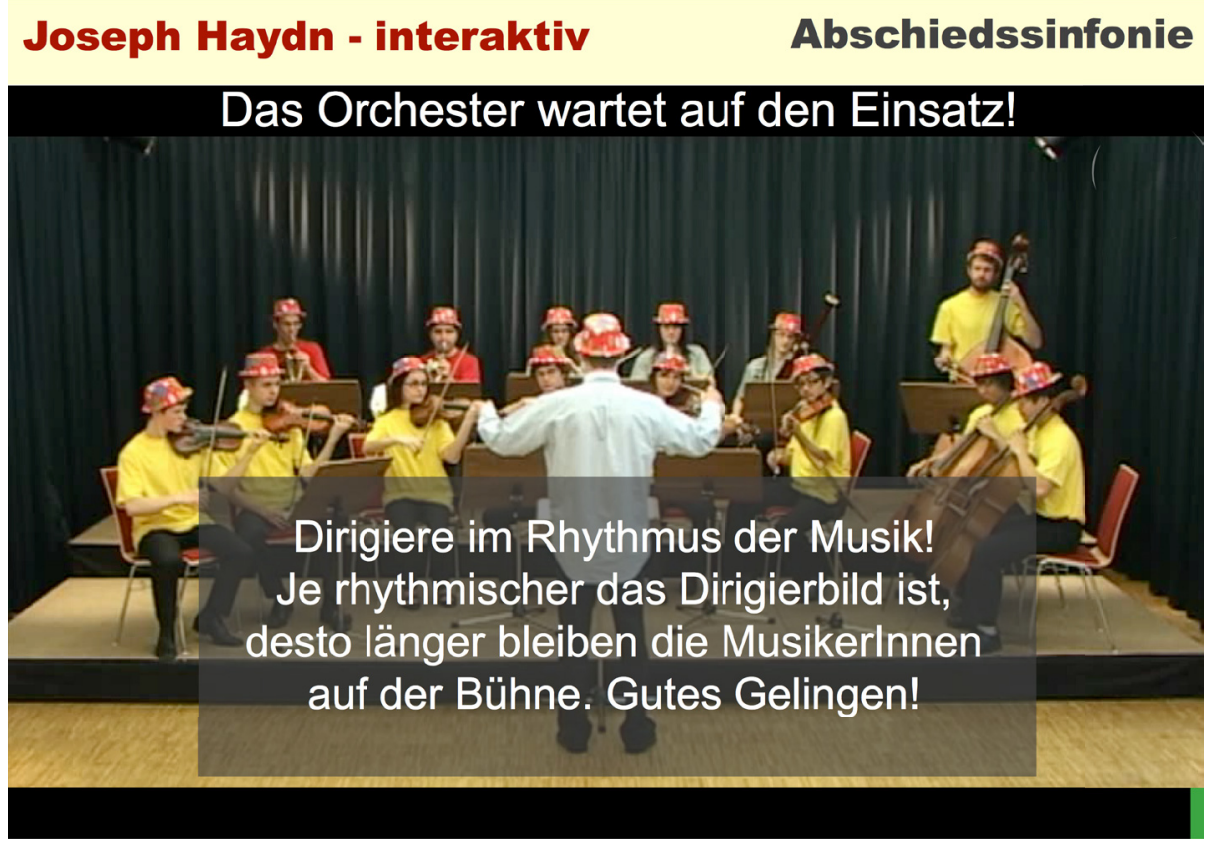

Fig. 1. Interactive motion controlled video

Working with commenting assignments we haven't made improvements in the last years. Written feedbacks are appearing in separate parts of the web page; comments and the timeline of the video are not in sync. For the main purpose of working with the videos this method is working, but it is not as practicable as synced text in public video platforms like Youtube. Another study has shown, that students don't like to give feedback to others by typing, this situation is getting worse when they are told to record own audio or video comments. In most of our commenting situations they just do it to get credits for a course.

\section{Survey of E-Learning Usage}

We surveyed 400 teachers in October 2016 and we got returned 189 completed forms. 50 percent of them mentioned, that they are using e-learning. Our Moodle system is counting 162 registered teachers and 1900 students in March 2017. The number of activities varies between 15.000 and 30.000 per month, higher amounts of activities are recorded at ending times of terms. $40 \%$ told that they are using Powerpoint very often, where $20,7 \%$ said, they don't need it at all. And yes, most of us agree, that Powerpoint and e-mails are counted to e-learning scenarios. Although 2 out of 3 persons are still using e-mails to communicate; $43,5 \%$ have digital materials to enrich their face-to-face teaching scenarios. Just $9,3 \%$ are using interactive computer or web based trainings, at least $25,7 \%$ are using such trainings rarely and $28,4 \%$ 
want to integrate such trainings in their field of education. More than $80 \%$ are using websites in their education, animations and simulations are part of digital learning in only $38,7 \%$. 1 out of 3 persons says that they don't need animations and simulations at all. Online tests and quizzes are not implemented; more than the half don't even think about the usage of multiple choice tests yet. Chatrooms are no longer interesting; weblogs, wikis and forums are in use from about $70 \%$ of the asked persons. Audio and video conferences are just held from 1 out of 3 teachers, $40 \%$ told that they are not interested in such conferences. They prefer to travel and meet people in real life. The time for cooperation in shared workplaces seems not to be ready, just $2,7 \%$ are cooperating online right now, 29,7\% want to start with it in the future.

Answering in a google survey seemed to cause no problems; all answers were sent in less then five days.

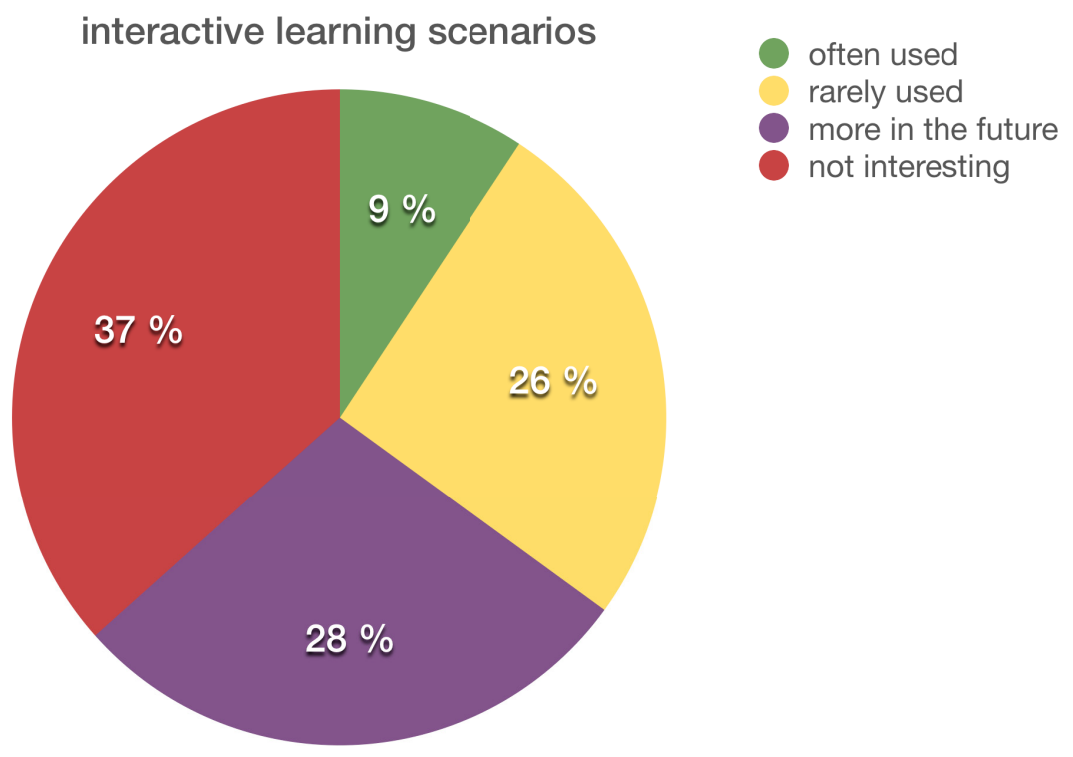

Fig. 2. music teachers at our university about the usage of interactive learning scenarios

\section{$4 \quad$ Podcasting}

The well known web tool loudblog stopped their development, so the missing integration of ldap for authentication let us decide to stop this podcast platform with a few hundreds of audio episodes. After a close rescan of the available podcast module in Moodle we then moved the best student produced podcasts into the Moodle podcast module and right now every teacher is involving his own course material, the production of podcasts has decreased significantly. Although a lot of publications are describing the power of podcasts the students right now in 2017 do not agree in seeing advantages for there learning environment. 


\section{$5 \quad$ Interactive Orchestral Scores}

With the wish of continuous improvements of multimedia content the latest music based animations were created with Adobe Animate. The digital material would be great on surfaces like tablet computers, but our university doesn't have a single device. The students are still not using private tablet computers in a quantity to get them involved with this equipment in significant learning processes. Some of them are using smartphones for searching the web and especially for social tools, many of our students are using university infrastructure for their e-learning situations; windows based personal computers in computer rooms. We are still focusing on production of interactive scores either on orchestral pieces and otherwise on choral scores. These advanced interactive apps are showing synchronized animations to streamed audio files. Streaming makes it also possible to use larger audio documents with animations and scores simultaneously by a group of students. So the listeners get possibilities to concentrate on single instruments, groups of instruments or the whole orchestra. The production of every single animated score is still a time-consuming process. The three main steps are building the digital score, recording the instruments and programming the animation.

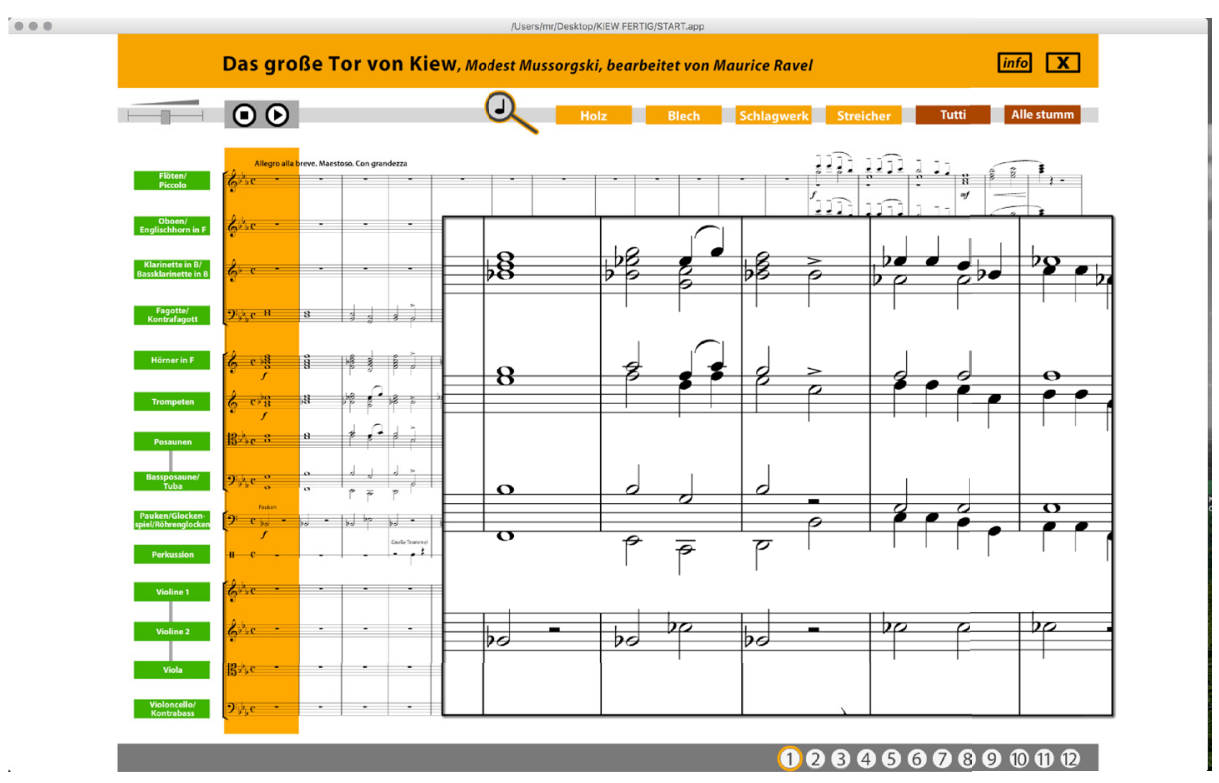

Fig. 3. Animated interactive score

In this animated score of Modest Mussogskys "Pictures at an Exhibition - Great Gate of Kiev" the music was build with sampled software sounds, the different instrument groups can be soloed or muted without being recorded in front of a microphone separately. Because of the complexity of the staffs there is a "zoom in" function added. The score will automatically be followed while playing with highlighted 
bars. Producing play-along scores for active listening to different kinds of music is a much easier procedure. We see advantages of this method in the very simple design of musical sections without traditional paper scores. While listening you can concentrate on the music and get involved with the piece of music when playing body percussion instruments like snipping, clapping or tapping according the symbols.

Concerto grosso Op. 6 Nr. 8, Allegro Arcangelo Corelli, Weihnachtskonzert
Manfred Rechberger (c) by Helbling, Rum/Innsbruck

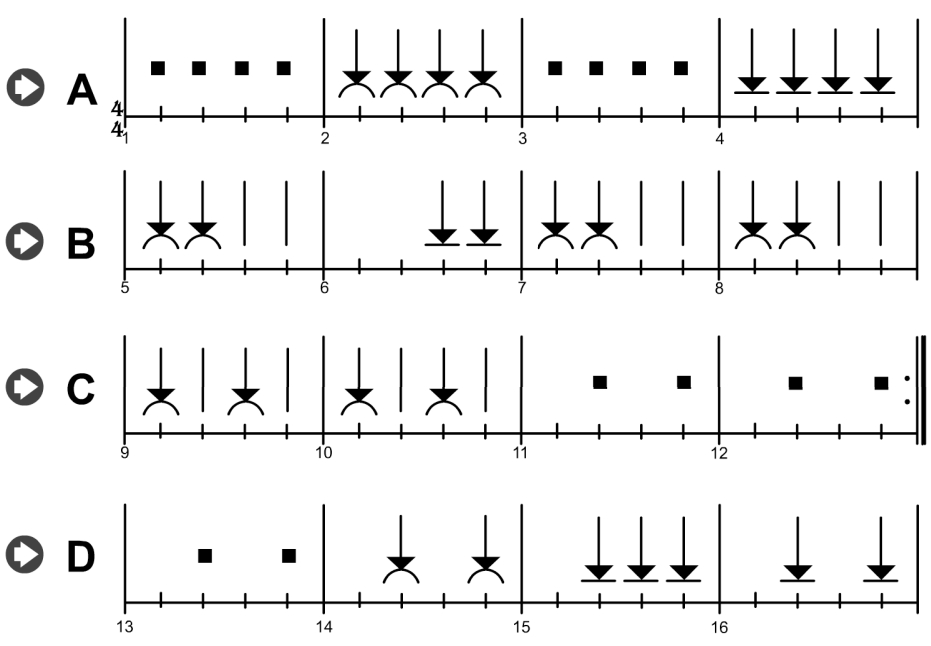

Fig. 4. Animated play-along score

\section{Some Facts of Austrian E-Learning}

In 2016 a group of scientists researched the e-learning behavior of Austrian universities. From 41 institutions mentioned 21 to use e-learning for longer than 10 years, 20 for 6 to 10 years and the rest of 8 have also started in the last 5 years. Most of them are using courses in the style of blended learning. Game-based learning situations seems to be installed in just 16 universities, followed by MOOCs; only 8 institutions mentioned to have own ones. All Austrian universities have in common, that they use just one central LMS; although the system is not everywhere the same. Moodle wins, some have adapted Moodle versions with own names. The survey shows a lot of potential in developing virtual classrooms, digital exams and e-portfolios. Some fields of study with high number of students have really professional rooms for digital exams, extremely booked up at the end of terms. Open educational resources are becoming more and more important. Especially when exchanging digital content the universities start to share their generated content a lot of more often than years ago. Most of Austrian universities argue, that the main reasons for more e-learning should make the accessibility to studies easier. 


\section{Summary}

E-learning scenarios are getting integrated in regular teaching situations at the University of Music and Performing Arts Graz since 2004. About 170 artists and researchers are developing their own e-learning landscapes in very different levels. This article handles the notably increased usage of e-learning at our university in 2017 with a special focus on development in the last 10 years. 250.000 people are living in Graz, about 50.000 students make the beautiful city to a very attractive place for studying. The e-learning activities at the different universities are starting to get linked; there is a common e-learning skill enhancement program running at www.edidactics.at. Each university and college of higher education in Graz organizes at least one part of a 2-3 year advanced training program. Whereas the typical tools forum, assignment and wiki cover most of the e-learning activities in the Moodle installation, podcasts and audio- and video implementations are becoming more and more important and popular. A last year's survey demonstrates the technical habits of artists and researchers in the field of music education, there bears a resemblance to an Austrian-wide survey with participants from all universities in our country in 2016.

From the didactical point of view, for instance, it is desirable to drop the straightjacket of course orientation with complicated file management in favor of more open learning types. Furthermore, it will still be necessary to develop suitable and viable synchronous communication types. Therefore, critical research is a technical and didactical adaptation of the Moodle platform, tailored specifically to the demands of our university - including the development of specific modules and their optimal preparation and treatment for teaching purposes.

Cooperative learning scenarios allow the involvement of students in research of access to art in a hitherto unknown dimension. Concerning the designated e-learning applications our university will be able to build upon previous achievements by the Institute of Music Education.

The usage of online tools has changed our thinking, music learning and music making; new options and opportunities especially for sharing work in online clouds become more and more important. At most of the considered studies success of online learning depends on communication using text, we still prove to focus on audio- and video based content and the sharing of these file types.

In the near future one important aspect of the research activities will be the linking and integration of the developed learning platform with video streaming devices, thus allowing the inclusion of the entire field of multimedia in e-learning landscapes independent from place and time.

Future e-learning activities: This contains e-learning models for education practice, development of interactive orchestral scores, play-along scores and musical games for teaching practice, development of modules and plug-ins for learning management systems, implementation and didactical design of the Moodle learning platform for lectures at our university. 


\section{$8 \quad$ References}

[1] Arch, Dave; ENSZ, Sue: Web-Based Interactive Learning Activities. HRD Press. Amherst 2001.

[2] Bratengeyer, Erwin; Steinbacher, Hans-Peter; Friesenbichler, Martina; Neuböck, Kristina; Kopp, Michael; Gröblinger, Ortrun; Ebner, Martin: Die österreichische Hochschul-ELearning-Landschaft. http://www.fnm-austria.at/fileadmin/user upload/documents/Studie/ E-Learning-Studie 2016.pdf. Februar 2016.

[3] El Saddik, Abdulmotaleb: Interactive Multimedia Learning. Shared Reusable Visualization-based Modules. Springer Verlag. Berlin Heidelberg 2001. https://doi.org/10.1007/ 978-3-642-56790-2

[4] Hills, Howard: Individual Preferences in E-Learning. Gower Publishing Ltd. Hampshire 2003.

[5] Holmes, Bryn; GARDNER, John: E-Learning. Concepts and Practice. SAGE Publications Ltd. London 2006.

[6] Mantyla, Karen: Blending E-Learning. The Power is in the Mix. ASTD. New York 2001.

[7] Müller, Thomas: Anwendung und Mehrwert musikbezogener digitaler Medien im Bachelorstudium Lehramt Sekundarstufe Allgemeinbildung für das Unterrichtsfach Musikerziehung an der Kunstuniversität Graz. Fachhochschule Burgenland 2016.

[8] Reinmann, Gabi (2013): Didaktisches Handeln. Die Beziehung zwischen Lerntheorien und Didaktischem Design. Hg. v. M. Ebner und S. Schön. http://13t.eu/homepage/dasbuch/ebook-2013/kapitel/o/id/93/name/didaktisches-handeln. 2017

\section{$9 \quad$ Author}

Dr. Manfred Rechberger is with the Institute of Music Education, University of Music and Performing Arts, Graz, Austria (manfred.rechberger@kug.ac.at).

This article is a revised version of a paper presented at the International Conference on E-learning in the Workplace 2017 (ICELW 2017), held in June 2017, at Columbia University in New York, NY, USA. Article submitted 15 March 2017. Published as resubmitted by the author 26 April 2017. 